\title{
Title:
}

\section{Emphysematous hepatitis: a very rare entity with a poor prognosis}

\section{Authors:}

Beatriz Estébanez-Ferrero, Orlando Fuentes-Porcel, Miguel Ángel Lorenzo-Liñán, María del Mar Rico-Morales

DOI: $10.17235 /$ reed.2021.7795/2021

Link: PubMed (Epub ahead of print)

Please cite this article as:

Estébanez-Ferrero Beatriz, Fuentes-Porcel Orlando, Lorenzo-Liñán Miguel Ángel, Rico-Morales María del Mar. Emphysematous hepatitis: a very rare entity with a poor prognosis. Rev Esp Enferm Dig 2021. doi:

10.17235/reed.2021.7795/2021.

This is a PDF file of an unedited manuscript that has been accepted for publication. As a service to our customers we are providing this early version of the manuscript. The manuscript will undergo copyediting, typesetting, and review of the resulting proof before it is published in its final form. Please note that during the production process errors may be discovered which could affect the content, and all legal disclaimers that apply to the journal pertain. 


\section{IPD 7795 inglés}

\section{Emphysematous hepatitis: a very rare entity with a poor prognosis}

Beatriz Estébanez-Ferrero, Orlando Fuentes-Porcel, Miguel Ángel Lorenzo-Liñán and María del Mar Rico-Morales

General Surgery and Digestive Diseases Service. Hospital Universitario Torrecárdenas. Almería, Spain

Received: 18/01/2021

Accepted: $20 / 02 / 2021$

Correspondence: Beatriz Estébanez-Ferrero

e-mail: beatriz987654@hotmail.com

Conflict of interest: the authors declare no conflict of interest.

\section{Case report}

A 67-year-old female, with no alterations in glucose metabolism or other relevant history, presented to the Emergency Department due to abdominal pain and vomiting after a syncopal episode. Physical examination revealed a poor general condition, mild stupor and a distended abdomen, painful on palpation in the right hypochondrium, with localized rigidity. On arrival at the Emergency Department, the patient's blood pressure (BP) was 150/66 $\mathrm{mmHg}$, heart rate $(\mathrm{HR})$ was 110 beats/minute and temperature $35^{\circ} \mathrm{C}$. Laboratory tests on admission were glycaemia $388 \mathrm{mg} / \mathrm{dl}$, aspartate aminotransferase (AST) 2,345 U/I, alanine aminotransferase (ALT) 2,174 U/l, amylase $70 \mathrm{U} / \mathrm{l}$, C-reactive protein (CRP) $30.44 \mathrm{mg} / \mathrm{dl}$, leukocytes 22,950, neutrophils $94 \%$, procalcitonin $86.58 \mathrm{mg} / \mathrm{ml}$, albumin $2.7 \mathrm{~g} / \mathrm{dl}, \mathrm{Hb} 13.5$ $\mathrm{g} / \mathrm{dl}$, platelets $102 \times 103 / \mu \mathrm{l}$, prothrombin time $63 \%$, international normalized ratio (INR) 1.35 and fibrinogen $570 \mathrm{mg} / \mathrm{dl}$. Initial venous blood gases showed pH 7.25, pCO2 48.9 mmHg, pO2 $339.3 \mathrm{mmol} / \mathrm{l}$ and $\mathrm{HCO} 320.8 \mathrm{mmol} / \mathrm{l}$. Computed tomography (CT) (Fig. 1) revealed a hypoattenuated area of geographic margins in the right hepatic lobe extending through segments VI, VII and VIII, with abundant air in the hepatic parenchyma at this level. 
Calcifications in the aorta were highlighted in the sagittal section, which could suggest a primary ischemic origin of the process, but it was unlikely given the absence of ischemic antecedents in other locations and no disturbance of afferent or efferent flow on the CT scan. Due to the septic symptoms, urgent surgery was performed via a right subcostal laparotomy, performing drainage, debridement and placement of an intrahepatic Foley catheter for lavage. The culture was positive for E. coli.

After a torpid postoperative course, the patient required prolonged systemic antibiotic therapy and percutaneous drainage (pigtail) of the residual hepatic collection (Fig. 2). Finally, she was discharged. After three years of follow-up, she remains asymptomatic and the ultrasound control only showed a scarred area in segment VII.

\section{Discussion}

Emphysematous hepatitis is a rare entity, with rapid progression and a frequently fatal outcome (1). Diagnosis requires high clinical suspicion and imaging techniques. Its occurrence is favored by any state of immunosuppression, such as diabetes and cancer (2). The most frequently implicated bacteria are Streptococcus mutans, Enterococcus faecalis, E. coli, Klebsiella, Enterobacter, Pseudomonas and Proteus (1-3). Emphysematous changes in the liver can occur in different clinical scenarios involving anaerobic microorganisms such as superinfected liver hematoma, after invasive procedures such as sphincterotomy, radiofrequency ablation or ethanol injection in hepatocellular carcinoma and in posttransplant hepatic artery thrombosis (2). Given its rapid progression and the ineffectiveness of percutaneous drainage, urgent surgical debridement seems the only alternative to try to avoid total liver parenchymal replacement $(2,3)$. Even so, it is an entity with a poor prognosis.

\section{References}

1. Nada KM, El Husseini I, Abu Hishmeh ME, et al. A rare case of septic shock secondary to emphysematous hepatitis. Case Rep Crit Care 2017;2017:3020845. DOI: $10.1155 / 2017 / 3020845$

2. Ghosn $Y$, Abdallah A, Hussein Kamareddine $M$, et al. Gas forming liver abscess versus emphysematous hepatitis: a radiologic diagnostic dilemma-a case report and review of the 
literature. Case Reports Hepatol 2019;2019:5274525. DOI: 10.1155/2019/5274525

3. Kim JH, Jung ES, Jeong $\mathrm{SH}$, et al. A case of emphysematous hepatitis with spontaneous pneumoperitoneum in a patient with hiliar cholangiocarcinoma. Korean J Hepatol 2012;18:94-7. DOI: 10.3350/kjhep.2012.18.1.94 

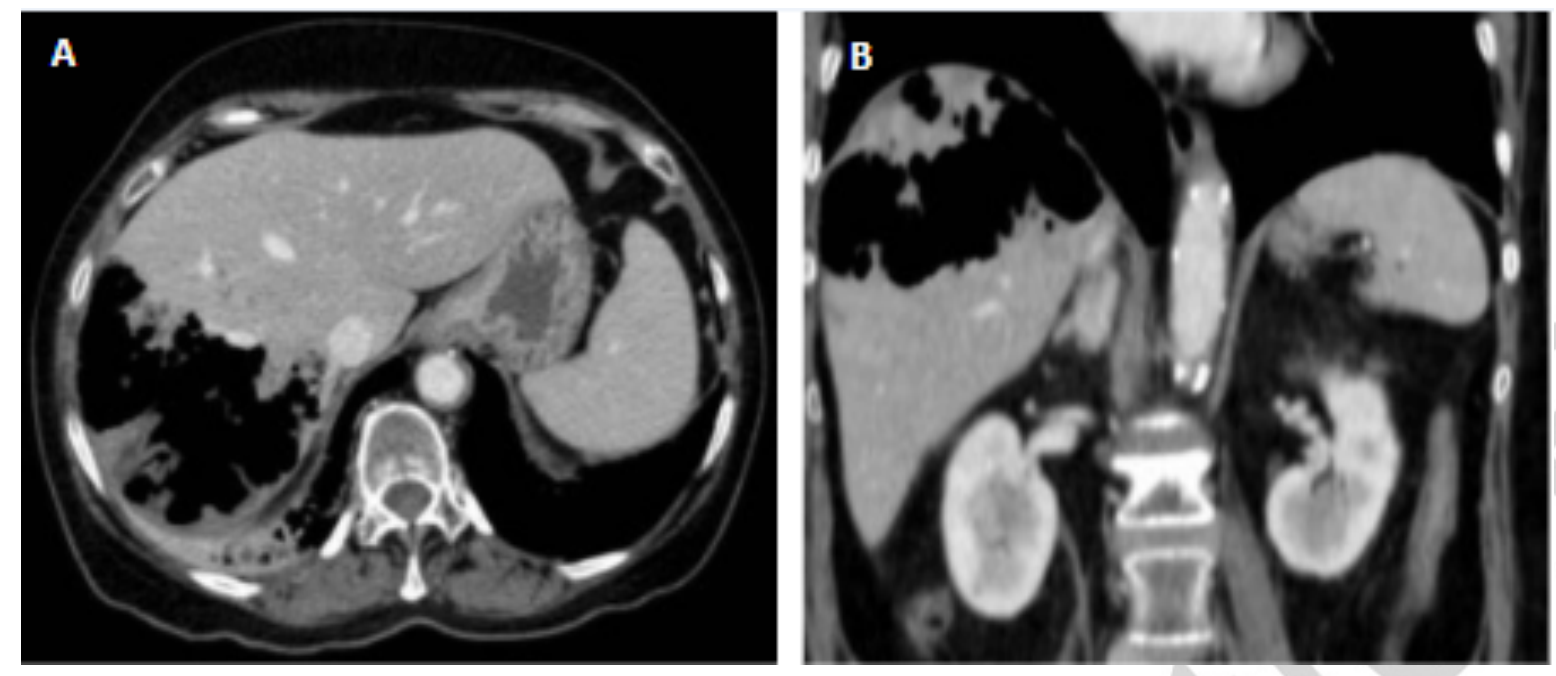

Fig. 1. Abdominal CT. A. Axial section. B. Coronal section. Hypoattenuated area suggestive of hypoperfusion, which extends through segments VI, VII and VIII, with abundant air in the hepatic parenchyma at this level. 

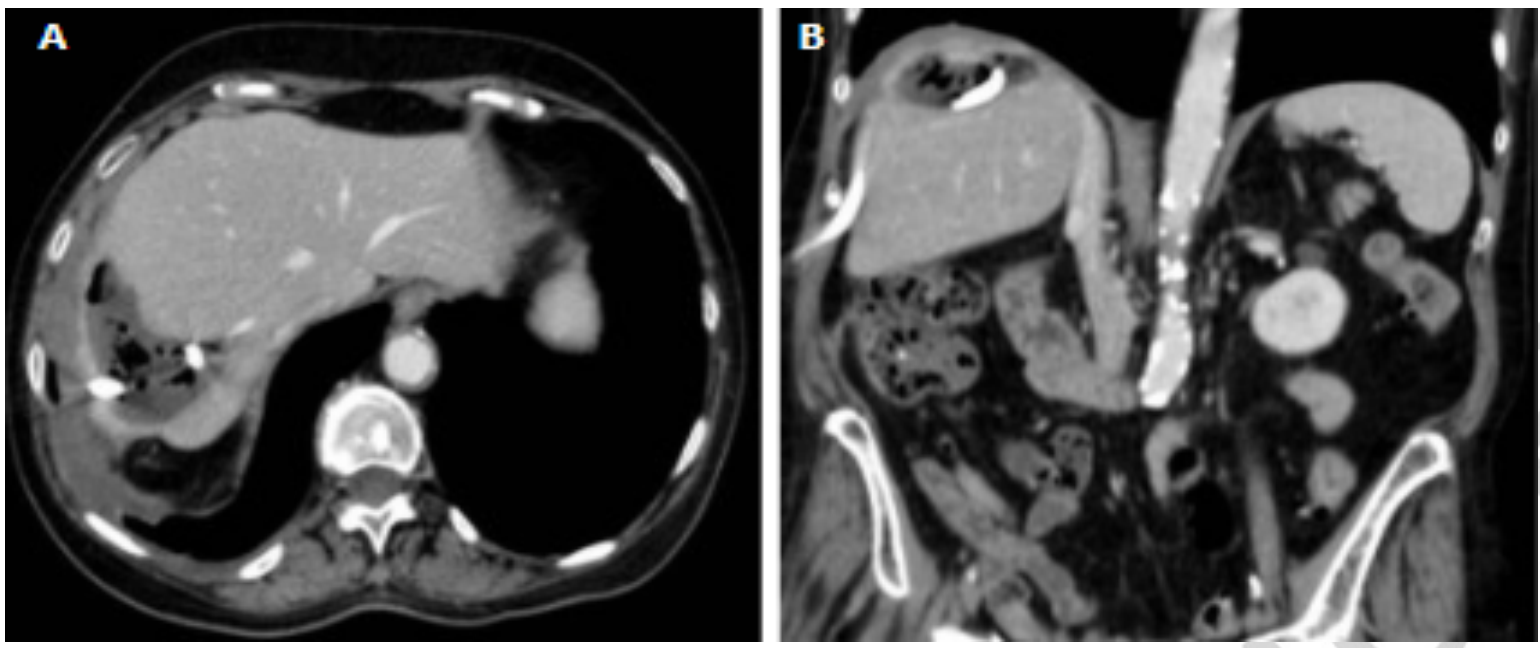

Fig. 2. Abdominal CT after surgery. A. Axial section. B. Coronal section. Very significant reduction in the size of the liver abscess in segment VII, with pigtail drainage in its interior and practical resolution of the adjacent hypoattenuated areas. 


\section{COMMENTARY}

Emphysematous hepatitis is a rare entity with a non-specific clinical phenotype but characterized by a rapid progression that could lead to poor prognosis within 48-72 hours. $E$. coli, Klebsiella, Enterobacter, Pseudomonas, Proteus and Streptococcus are the most frequent pathogens in this entity. Emphysematous hepatitis should be specifically suspected in diabetic patients. Typically, the liver shows gas in situations such as hepatic abscess, after sphincterotomy, intestinal ischemia, or even in cases of thrombosis of the hepatic artery after liver transplant. Early broad-spectrum antibiotics together with surgical debridement must be considered as the first therapeutic options.

Javier Ampuero

Associate editor of The Spanish Journal of Gastroenteology 